\title{
REVENUE MANAGEMENT: PROGRESS, CHALLENGES AND RESEARCH PROSPECTS
}

\author{
Xuan Lorna Wang, Cindy Heo, Zvi Schwartz, Patrick Legohérel*, Frédéric Specklin \\ London School of Hospitality and Tourism, University of West London \\ École Hôtelière de Lausanne \\ Alfred Lerner College of Business and Economics, University of Delaware \\ Granem, University of Angers \\ Disneyland Paris
}

\begin{abstract}
This paper evaluates the main developments of revenue management (RM) over the past decade and discusses RM challenges and research prospects. It examines nine notable emerging themes: total hotel revenue management, big data analytics, distribution, rate integrity, RM and marketing strategies alignment, social media impacts on RM, revenue management system, applications of RM in non-traditional service sectors, and RM education and training. We argue that these developments have far-reaching implications for real-world RM practice and anticipate that the topic areas will continue to be popular for hospitality and tourism research in the foreseeable future.
\end{abstract}

KEYWORDS: Total revenue management, big data analytics, distribution, rate integrity, customer relationship management, social media, revenue management system, education and training

\section{Introduction}

Revenue management is considered to be a mature field of study in operations management research (Dana, 2008). Different streams of research have emerged over the past decade to address the challenges faced by RM practitioners in the ever-changing marketplace, and these continue to improve our understanding about RM and its implications for other aspects of management. This paper has three main objectives: first, to provide an overview of the current state of knowledge in the area of RM research with a focus on the main developments achieved after the previous special issue was published in JTTM in 2004; second, to better understand how recent RM developments have 
informed us about new trends of RM practice and future research perspectives; and third, to engage and to initiate further discussions with RM practitioners about the future of RM and its implications for hospitality and tourism marketing management, which in turn should make progressive contribution to advance RM theory and practice. The next section presents the nine RM themes observed in the past ten years. Each of these is critically evaluated and their implications on RM practice and future research direction is also duly discussed.

\section{Total Hotel Revenue Management: What it is, what it is not, who gets it right?}

An important issue facing hotel revenue management is the concept of Total Hotel Revenue Management, or THRM. It relates to capturing the mostly untapped revenue and profit potential associated with the non-room revenue-generating centers of the hotel, or, in the words of Bonnie Buckheister, president and CEO of Buckheister Management, THRM is "Managing every revenue source at every guest touch point to its maximum profitability for the entire hotel or resort asset”. While the topic is discussed extensively by practitioners, it has received very little attention in the hospitality management literature in recent years. Four years ago, Kimes (2011) reported that, in her survey of industry professionals, the most common response regarding the future of revenue management suggests that RM would become more strategic in nature, and that it would encompass all revenue streams within the hotel. Function space, restaurants, spas, and retail were listed as the most likely non-room revenue centers to be included in revenue management. This industry sentiment is not reflected in our literature as little is published in hospitality and tourism academic journals on the topic. Among the noteworthy relevant works are those of Licata and Tiger (2010) and Rasekh and Li (2011) on golf courses, Kimes and Singh (2009) on spas, Handler and Handler (2004) on casinos, and Kimes and McGuire (2001) on function space. However, even these few studies seem to miss the point of "Total". These studies demonstrate a "local" approach to optimization within the non-room revenue center, as opposed to viewing the "big picture" where the concept of optimization considers the hotel in its totality. In other words, our academic discussion so far ignores the notion that these revenue centers are part of the hotels, and consequently their performance impacts, and is impacted by, the other revenue centers. As such, it does not fully address the interrelatedness of the 
non-room revenue centers with the rooms' and the other centers functions. This "computational isolationism" is likely to result in sub-optimal outcomes regardless of how effective the employed isolated optimization methods are.

Meanwhile, as noted above, the industry seems to embrace the concept of THRM and at the same time to acknowledge a gap and a need for better tools. There is a divide between the volume of discussion and buzz around the concept of THRM generated by the industry and the actual level of effective implementation. For several years now, industry leaders and hotel companies have regarded THRM as one of the most desirable advancements in the field. While there seems to be an industrywide consensus about the necessity to switch to THRM, little is known at this time about how that could be done correctly. Consider for example the following thread of industry quotes, demonstrating the realization that something is "missing”.

An early (HSMAI, 2010) blog on the topic by the Hospitality Sales and Marketing Association International (HSMAI)'s Revenue Management Advisory Board states:

"Many companies are now realizing that there is a strong need to adopt a more holistic approach to revenue management across the enterprise. This involves two distinct components. First, there is a need to capture and track all revenue associated with hotel guests in order to segment customers more discretely based on their value -- this can come from food and beverage, spa, event venues or, in the case of a casino/hotel, gaming. Second, and equally important, operators need to begin to apply the same principles of revenue management employed at the hotel to each discrete revenue source -- there has been a strong push for revenue management in restaurants, spas, event venues and even on the casino floor".

Three years later a member of the same advisory board seems to distance herself from the second point above. According to Farley (2013), the President of Rainkamer, a market leader in profit 
optimization solutions for the gaming and hospitality industries:

“...hotels employ astute controllers and support staff thoroughly capable of calculating the marginal value of, say, sleeping room profitability vs. restaurant profitability vs. lounge profitability... It is one thing to know that restaurant profitability is, on average, $x \%$, but quite another to connect that understanding to behaviors characteristic of identifiable categories of guests. Total hotel revenue management is a most worthy objective, one that surely will be achieved in stages, but one that also will require a more disciplined, connected set of operational and analytical practices.”

Interestingly, it seems that the industry might indeed be ahead of academia in understanding the nature and challenge of true THRM. Here is an even clearer example. Origin World Lab (2014) states that THRM is not about the application of revenue management concepts to revenue streams other than rooms, such as Food and Beverage (F\&B), Spa and Golf, among others (that make up the total hotel revenue) but rather it is "when the interconnected relationships across revenue streams are considered simultaneously in order to create a bundle of prices that optimizes the hotel's total bottom line.”

Similarly, in conjunction with the announcement of their new function space-optimizing module, IDeaS (2014) states in a recently released white paper:

“...considering overall profit, predicting group demand, and pricing with demand in mind, your organization will realize several benefits. First, you'll fill your function space better, which will increase revenues and profit. Your team will better understand the contributions of various revenue streams and when to make a tradeoff between streams, such as food and beverage versus meeting room rental. If your sellers can convince a group to pay for meeting room rental, they understand that goes directly to the bottom line and will help the hotel in the long run..." 


\section{Academia or industry, practical challenges, and research opportunities}

While we as an academic discipline might have made a late start on THRM, the practical and theoretical challenges associated with the topic present several exciting opportunities for academic research. Clearly the "Holy Grail” in this regard is the mathematics (Origin World Lab, 2014) as the complexity of the optimization increases considerably once we start adding revenue centers to the equations. While it seems that some RM solution providers are starting to offer integrated models, mostly in the area of casinos, and now meeting space, much more work is needed. Some additional interesting THRM research venues include the question of profit vs. revenue orientation, time horizon and big data analytics.

The realization that one should optimize the entire hotel rather than rooms only underscores the need to re-examine the current heavy reliance on revenue optimization. A recent study by Schwartz, Altin and Singal (2014) provided initial evidence that the assumptions regarding optimal revenue being sufficient to ensure near profit maximization is most probably less likely to hold true when more revenue centers beyond rooms are added to the mix. This issue is relevant to both the control-setting phase where most algorithms are revenue-based and the monitoring phase of the revenue management cycle where there is an industry-wide convention of almost sole reliance on revenue-based measures such as RevPAR instead of profit-based measures.

All three RM cycle phases (forecasting, control setting and monitoring) are of concern when it comes to the planning time horizon. That is, the move to THRM is associated with a paradigm shift from the tactical/short-term mindset to a strategic/long-term view. This shift implies that we need to modify the forecasting methods we use, to ones which effectively handle longer forecasting horizons, adjust optimization methods to ones that could incorporate longer term elements, and, of course, adopt outcome measures that are more suitable for long-term evaluation. In the case of the control-setting phase in particular, as articulated by some RM solution providers, the move to THRM means that optimization methods should be considering global rather than local maxima in the sense that much 
more is involved in the output functions as we add revenue centers to the mix. Since the production of the various revenue-generating departments is often interdependent, it follows that simply optimizing each department independently is most likely to generate suboptimal outcomes. The proper approach would be to optimize simultaneously while taking all departments and their interdependency into consideration or, in other words, to consider the customer's total value across the hotel's various revenue-generating centers.

\section{Big data analytics}

There is a new exciting area of big data analytics. Simply stated, the term big data refers to the fastgrowing availability of structured and unstructured data, characterized by large volume, velocity, and variety. Big data can contribute in improving all three phases of the revenue management cycle consider, for example, how more accurate demand forecast could be if clickstream information is entered into the models and how the hotel's competitive set could be constructed to reflect consumer perspectives rather than the current approach of similarity of hotel characteristics. At the same time big data analytics presents an unprecedented opportunity for a paradigm shift in the practice revenue management. Current revenue management systems contrast rooms' inventory with predicted demand by segment. The predicted demand and assessed probability determines decisions such as how the inventory (rooms) are allocated to rate fences, distribution channels and how many rooms to overbook. As noted by Tim Coleman (2013) big data has the potential to support instantaneous decisions (e.g., on whether to accept or deny a booking request) based on "live information about the guest, the hotel, the city and millions of other data points where available". In economic theory terms what the industry is so excited about is that big data will support a move away from the less efficient, thirddegree, price discrimination model as currently practiced by the industry towards the first-degree, perfect, price discrimination model where the vast majority of the consumer surplus could be extracted by the hotel. A big-data-based system will have immediate and dynamic access to information about each customer. Such information comprises online activity directly or indirectly related to the reservation including search patterns, booking and post purchase evaluations, rates paid in the past for hotel rooms and other products, guest profile, consumer/psychological profile, time of 
travel, loyalty patterns, time of booking, the mode of transportation, the customer's response to various marketing efforts in the past and weather at the origin and destination among others.

When this real-time big data information is combined with similar information about other potential future guests' reservation requests, it could be used to individually tailor the product and price combination; that is, the room and room rate quote. With the ability to best assess the individual guest needs, wants, and willingness to pay, the goal of true, most efficient optimization might be within our reach. Academia can and should play a major role in advancing our understanding of these issues and suggesting and testing proper solutions.

\section{Revenue management and distribution}

Distribution channels expansion is a mandatory step to develop business growth in the tourism and travel industry: it means to deal with new technologies, worldwide complexity and powerful partners. According to Vinod (2004), the arrival of the internet and its online supermarkets has led academicians and researchers to revisit the merchant model and to fit with demand generation via Edistribution channel. Forgacs (2010) reminds that the strategic objective of distribution channel management is three-fold: revenue producer, cost effective and easy to control. As specified by Vinod (2009), RM and product distribution are inextricably linked to each other, distribution being the storefront that displays products according to RM recommendations. This section focuses on the distributors, the so-called indirect channels because it raises additional revenue optimization challenges we intend to develop.

Distributors can provide pure hosting services (for instance the Global Distribution System) billed as a fee, act as a travel agency selling the products within their own processes and systems against a commission, or repackage the product into broader packages including a mark-up as a Tour Operator or through third-party websites (Toh \&Al, 2011). Distributors have to generate an incremental demand in order to offset the commission and distribution fees. Otherwise this would result in just 
cannibalizing the existing goodwill.

For Mauri (2013), channel management has arisen as a crucial component of RM. Whether to differentiate inventory access between direct channel and trade, however, is highly debatable. For the sake of partnering principles and to facilitate the sales dialog inventory access should be strictly the same. However, revenue-speaking, the service producer should offer a wider availability of access to its own direct customers in order to reduce the volume of commissions and distributor fees. RM decisions are usually based on maximizing expected net contribution, and incremental costs are to be incorporated in the inventory control model (Phillips, 2005). Inventory access will be managed differently for direct and indirect channels when fees and costs are integrated in the revenue contribution. Then more availability opportunities will be assigned to the direct channel especially during the constrained periods and when there are few remaining unities to sell. On the other hand, the revenue contribution is calculated in gross revenue when the availability management policy is nondifferentiation.

Securing availability access to partners during the most constrained periods is a major consideration. The yearly agreements could include some dedicated allocations to protect capacity for the partners instead of managing it through free sale only. These allocated capacities are managed by the RM team and the contracted capacity allocation is the result of intensive sessions between the RM and the sales division acting as a spokesperson for the partners. Introducing an allotment policy into the reservation inventory is a considerable responsibility and brings with it a weighty additional workload because it implies daily monitoring to comply with the agreed contracts while applying special sales conditions. RM performs the proper analysis to allocate the right level of capacity to trade partners by first assessing the direct channels potential as a basis and then by identifying the forecasted remaining capacities to be proposed for the partner's allocation.

In case of a high-discounted campaign run with a specific partner, the RM function is to steer and limit the demand over the weakest periods. As mentioned in Noone (2003), RM strategy can be 
adjusted with some partnering efforts including availability guarantees, dedicated pricing or promotions to support "true friends" partners, according to customer segmentation proposed by Reinartz and Kumar (2002), over a long-term profitability vision that outweighs any short-term rate dilution.

Channels management implies the capability to build mutual agreements based on the proper tradeoffs on a yearly basis and the capacity for the RM to perform two-tier performance measurement: traditional RM performance for the direct channel and a second one including Lifetime Value for trade. The long-term risk is not negligible because the cycle of tough negotiations with major partners tends to result in the transferring of significant margins from the services producer to its distributors, and business-to-business (B2B) relationships could turn the service producer into a simple sub-contractor providing raw products with a limited margin. RM plays the role of counterbalancing the pressure by providing revenue and profitability insights, and should be associated more with strategic decisions related to channels management. According to Venkat (2009), this could be through a move from the traditional RM to profit optimization by integrating RM, Marketing Pricing and Distribution toward consistent data, synchronized analysis and coordinated actions in response to corporate requirements.

Channels management is finding the right compromise between demand generation and revenue leakage over a long-term horizon. Taking back control over product distribution is becoming a priority and efforts are made to modernize the direct channels devices: web portal designing, smart media development, search optimization engine and call center streamlining. Improvements may focus on processes and analytical tools for reinforcing the RM role, thus leveraging different fare and availability policies depending on the channel in use.

\section{Revenue Integrity: practical challenges and research opportunities}

Ten years ago reports from industry referred to new principles aiming to stem revenue leakage and to yield more revenue improvements and cost reductions. Rose (2007) published one of the first academic papers focussing on revenue integrity (RI) which was described at the time as "an ignored 
practice in the area of revenue management”. Holloway (2008) indicated that RI efforts are to ensure as far as possible that the revenue anticipated when a reservation is accepted does actually materialize. Most pioneer authors were from airlines but, surprisingly, industries, including telecommunications and healthcare, have first taken advantage of RI in order to minimize costs and maximize revenue. RI approaches were developed later in airlines, and then were also implemented in other companies in different sectors (including hospitality and theme park).

Ten years after RI is now fully considered by the industry as an option to improve companies' efficiency. IT businesses have developed solutions for services companies to implement RI processes; for instance, Amadeus Revenue Integrity Platform, Sabre Air Vision Revenue Integrity, and others, offer airlines solutions to implement RI processes, and improve global revenue management approaches. Literature also clearly refers to RI and considers that the RI concept and processes should be developed along with global revenue management, in order to reduce cost, stem revenue leakage, and increase benefit (Legohérel, Poutier \& Fyall, 2013). Nowadays, some job employment ads even refer to specific RI profile and skills (some were offered on the job market this year - 2014).

\section{Revenue integrity objectives and research perspectives}

Niffoi (2013, in Legohérel, Poutier \& Fyall) indicates that the goal of RI is to ensure the integrity of revenue; that is, the consistency of the entire commercial chain from price definition through price charging in booking systems, proper application of price conditions, and respect of yield determined sales recommendations to final invoice clearance. In most services companies, though, failures occurs both in the marketing and sales operations. This weaknesses fall into four categories: technical problems, procedure problems, communication problems and operational/behavioral problems. All weaknesses must be identified and corrected. Then, the expected gain ranges from $1 \%$ to $3 \%$ in additional revenue.

What about research? Despite the recent "real" development of RI over the last few years, academics have not fully considered this promising and exciting area of research. Some papers have referred to 
RI, but without focussing on this concept (Wishlinski, 2006). RI lies at the intersection between several disciplines, including marketing, financial and cost control issues, management (of sales teams, procedures, etc.), information technology and systems management, data tracking, human resource skills, and sales, among others. A more global view of revenue and benefit improvement has emerged, and more research is needed to investigate and improve integrated/global revenue management approaches. Some papers have recently considered this issue (including Steinhardt \& Gönsch, 2012). As many practitioners agree on solutions developed and implemented in order to strengthen the robustness and efficiency of RI, in the context of a more global/integrated approach of revenue/benefit management, there is a need for academics to contribute to this relatively new area of research.

\section{The alignment of marketing strategies and RM}

One of the most noticeable revenue management movements in the past decade is the alignment of RM and marketing strategies, with a common goal, in a more integrated manner. A number of major progresses including RM and CRM integration, exploiting opportunities offered by social media and more recently - reputation-led pricing strategies, have all positively influenced RM decision-making capability through better understanding of customer behavior, customer value and customer relationships. These improvements in turn pose new challenges for RM practitioners and require further research. Each of these areas is discussed below.

\section{Revenue management and CRM integration}

One of the notable developments in RM in the past ten years is the conceptual development of the RM and CRM interface. Understanding about customer perception towards RM has been greatly enhanced and the notion of integrating RevM and CRM has led the hospitality and tourism industry to 'a new era' (Mainzer, 2004: 285) but not without difficulties. Although RM and CRM should be two complementary practices (Wang, 2012), previous literature offers insufficient guidance on how to integrate CRM with RM at the strategic level (Mathies \& Gudergan, 2007; Milla \& Shoemaker, 2008, Von Martens \&Hilbert, 2011). A significant number of studies have been carried out in recent years to advocate the need for more research into this area and to seek a possible solution. For instance, based 
on a wide range of interviews conducted with industry leaders worldwide, Milla and Shoemaker's (2008:110) study identifies RM and CRM integration as one of the four major areas of "having the greatest growth potential in hotel RM'” and suggest that customer will become the driver of RM in the future. Pricing, market segmentation, group revenue management and organizational structure changes to optimize RM potential are key areas that require management attention. Echoing this view, Vinod (2008) suggests that customer-centric RM is a new paradigm for RM.

Customer-value based RM is also proposed to overcome the limitation of transaction-based RM by both utilizing capacity efficiently and establishing profitable customer relationships (Von Martens \& Hilbert, 2011). However, in practice, findings from the hotel industry reveal several causes of potential management conflicts that could become the hurdles for RM and CRM integration if not addressed (Wang, 2012; Wang and Bowie, 2009). These include management goals, management timescales, perceived business assets, performance indicators, and managers' approaches to achieving individual set goals. In a B2B context, the key account management and RM integration framework developed by Wang and Brennan (2014) is one of the first to amalgamate account management and RM through comprehensive analysis of the relationship and revenue value of an account that facilitates managers to make strategic RM decisions that aim for long-term profit yield.

The importance of recognizing customer value in the RM decision-making process has also been widely advocated by RM professionals. A number of opinion leaders and senior RM practitioners from one of the leading RM professional networks, Revenue Management and Pricing International (formerly Revenue Management Society) in the United Kingdom (UK) suggest that the ability to comprehend RM implications on online and offline marketing strategies and vice versa, is pivotal for the new generation of RM decision-makers especially in today's fast changing marketplace. Considering that RM evolves from its originally tactical inventory management to a more extensive role across the company and at a more strategic level, action research addressing relevant issues surrounding this topic area is expected to grow. 


\section{Revenue management and social media}

How to capitalize on opportunities offered by the rapid development of social digital marketing strategies such as social media to improve RM is another area of research that has attracted much attention in recent years. The effectiveness of using social networking sites, such as Facebook, Twitter, TripAdvisor and YouTube, as means to reach prospective customers, understand customer behavior, establish and maintain customer relationships, and influence customers' value perceptions has becoming a popular area for research. The fast growth of SM usage inevitably expands the spectrum of reputation risks and has boosted the risk dynamics (Aula, 2010; Eccless et al., 2007), thereby posing new challenges for RM practitioners. The framework for evaluating social mediarelated RM opportunities developed by Noon et al., (2011) undoubtedly have made progressive contribution to this relatively new stream of RM research. More sophisticated views of how consumers engage with brands have been revealed in the hospitality and tourism marketing literature, which will have profound implications for RM. For example, Hudson and Thal (2013) argue that social media have fundamentally changed the consumer decision process. They illustrate how social media make the 'evaluate' and 'advocate' stages of today’s 'consumer decision journey’ increasingly relevant based on the four stages of the consumer decision journey: consider; evaluate; buy; and enjoy, advocate and bond (Court et al., 2009).

The link between SM and RM has been substantiated in recent years, which shows that SM has impacted on revenue performance and reputation matters (Anderson, 2012) although research in this area remains limited. In a first attempt to establish return on investment (ROI) for SM efforts, Anderson's report (2012:5) reveals a number of significant findings. First, the number of reviews that consumers read prior to making their hotel choice has steadily increased over time. Second, a hotel can increase its rate by 11.2 per cent and still maintain the same occupancy or market share if their review scores increase by one point on a five-point scale. Third, hotel pricing power has been influenced by user reviews; one per cent reputation improvement could lead up to a 1.42 per cent increase in RevPAR. 
Industry leaders such as Patrick Landman, the CEO of XOTELS, an international hotel management company specializing in RM, predicts that a focus on corporate reputation is expected from the RM perspective in the years to come, as it is vital for companies to have a positive reputation and online review score in order to enhance its revenue performance. One of the leading RM system providers, IDeaS Revenue Solutions, launched its Advanced RM system - IDeaS G3 RMS in July 2014, which claims to be the first to allow hotels to use their current online reputations as a criterion for making pricing decisions. It is therefore fair to assume that in addition to more traditional pricing factors such as location and demand, future RM pricing decisions are likely to be made also based on a hotel's reputation. More studies in this particular area are needed to explore contemporary issues such as how RM could embrace the opportunities offered by SM and to comprehensively examine the effects of SM, customer reviews and their implications for a company's reputation and subsequently revenue performance.

\section{Revenue management system}

Revenue Management Systems (RMS) has its origins in the success story of the SABRE system at American Airline as described in Smith and Al (1992) and in Rothstein and Stone (1967). RMS are two embedded strategic Information Systems (ISs), a reactive loop with highly detailed data for tactics and a slower loop with aggregated information for supporting the strategy. For Queenan and $\mathrm{Al}$ (2011), IT is to be considered as a RM performance driver.

Talluri and Van Rysin (2005) consider RM as a computationally intensive process with large amounts of data, forecasts and a massive optimization produced on a daily basis. Hardware requirements are multiple with a large range of RM solutions on the shelf from the smallest software package for a medium size hotel to a several-millions-dollars modules suite proposed by major solution editors. RMS is constructed with data collections from operational systems Operational Research tools (forecaster, optimizer), the reservation system and interfaces with the distribution systems. Data exchanges are two-sided with the sending of availability controls (bid price, hurdle rates, booking limits) from the RMS and current bookings and the remaining availability from the operational 
systems. Since RMS encompasses at least three distinct inventories (Reservation, Operations and OR tools) that are to be synchronized around a single image for the data and systems integrity, the criticality of a RMS is high because the lack of control-setting could lead to significant loss of revenue. RM is a mechanical process with most of the routine decisions made supported by the system under the guidance of an analyst inserting adequate overrides, even if some judgment bias related to the User Interface have been observed, as in Schwartz and Cohen (2004a).

The performance measurement of RMS is covered in Rannou and Melli (2003). The system performance is to be assessed including the user actions for influencing the system. As suggested by Lieberman (2003), to increase efficiency, the RM analyst has to compensate the system limits and this is facilitated when users have a general technical understanding. RMS performance is a human challenge and should become a long-term goal shared with the editors involved.

New prospects for RMS building are user-oriented with, for instance, the user friendliness of web technologies or AGILE software development methods that offer the possibility to start from the user decision-making processes for designing screens and monitoring tools. The next generation of RMS should be more customer-centric (Vinod, 2008) with the generalized implementation of hybrid demand models incorporating the customer booking behavior as buy-down when a lower fare is available, set forth in Boyd and Kallesen (2004), Fiig and Al (2010) and Walczak and Al (2010), and the integration of customer profiling and tactics-building from tracking systems. Since technologies are ready for this challenge, some additional research is needed to develop analytical methods for exploiting the opportunities offered by the big data and social media in the RM field.

\section{Application of revenue management in non-traditional service sectors}

Revenue management has grown into a mainstream business practice in a variety of service industries (e.g., hotels, car rentals, restaurants, casinos, and theme parks), and even in some manufacturing industries. Airlines, hotels and rental cars represent three of the major sectors in which RM is applied, and abundant research has been conducted on these traditional applications of RM. However, 
researchers have proposed that its potential applicability extends to a number of other service industries with similar industry characteristics; in the last ten years for instance, researchers have explored various topics for the non-traditional RM industry. Chiang, Chen and Xu (2007) in particular presented research publications on the non-traditional RM industry.

Among non-traditional RM industries, restaurant RM is one of the most researched areas of the last ten years. Kimes (2008) discussed the role of technology in restaurant revenue management, Chan and Chan (2008) showed how the lunar-solar calendar-driven festivals affect Chinese restaurant operation and revenue, and a simulation study by Thompson (2009) found that reducing dining duration increases revenue only by about one-quarter of that expected. Thompson and Sohn (2009) found inaccuracies in the existing approaches to calculating RevPASH, a common metric of restaurant revenue performance, and Thompson (2010) presented a new decision-based framework for restaurant profitability. Heo et al. (2013) found the negative effects of price difference on customer's fairness perceptions in the context of restaurant RM, and Guerriero, Miglionico, and Olivito (2014) proposed a dynamic formulation of the parties mix problem with a linear programming approximation.

Another non-traditional RM sector is the cruise industry. Toh, Rivers, and Ling (2005) discussed room inventory management issues of cruise lines, and Biehn (2006) discussed the differences between cruise line RM and airline and hotel RM. Ji and Mazzarella (2007) meanwhile adopted nested class allocation and dynamic class allocation inventory control to cruise inventory and tested the viability and benefits under a simulated reservation process. Sun, Gauri, and Webster (2010) applied 24 forecasting methods to generate forecasts of final bookings for cruises and found that classical methods perform the best, followed by AP and lastly non-pickup methods. Sun, Jiao and Tian (2011) provided a review of the cruise industry from revenue optimization and marketing research prospects. Finally, researchers have also explored RM application in other sectors such as spas (e.g., Kimes \& Sonee, 2009), casinos (e.g., Peister, 2007; Chen, Tsai, \& McCain, 2012) and theme parks (e.g., Heo \& Lee, 2009). Although there have been studies on other non-traditional RM industries, most research focuses on how RM principles can be applied across sectors of the hospitality industry and on the 
application of existing techniques.

So far, revenue management systems (RMS) are available only for traditional RM industries, but in the future it is expected there will be new technologies and RM systems for non-traditional RM industries. While most current RMS for airlines and hotels are system-oriented, service-oriented RMS are to be introduced for non-traditional RM. Initial investment costs for service-oriented RMS should be lower than system-oriented ones and thus small business owners can readily utilize RMS to improve their revenue. The increasing number of smartphone users and the prevalence of Web 2.0 technologies may help non-traditional RM industries to control demand and to enhance revenue better than ever before. For example, mobile platforms and social commerce can be used for restaurant RM as distribution channels in the same way that hotels and airlines use online travel agencies. Also, location service technology will allow organizations to find customers within a defined area. Considerable additional research on non-traditional RM industries, particularly using new technology, may help organizations to maximize the benefits of RM.

\section{Revenue management education and training}

Revenue management has been credited with improving revenues in various sectors of the tourism and hospitality industry and many companies have now realized its importance. Companies have invested significant resources, in particular in RM systems, and have elevated its importance within their organizational structure. Consequently, there is an increasing demand for knowledgeable revenue managers.

Hospitality schools started to offer revenue management courses during the past decade, and now most programs include an RM course as a core subject. Several universities provide certificate programs for industry practitioners and even Masters’ Programs specializing in RM. Examples include the University of Angers in France, which runs a Masters’ Program in Service Marketing and Revenue Management, and Cornell University in the United States (US) which offers a Master's Certificate in RM. Executive Development programs such as the Frontier in Revenue Management 
offered by the Winter School of the Hong Kong Polytechnic University and the University of West London, and Pricing Analytics offered by the Center for Pricing and Revenue Management of Columbia University in the US are also available. Private institutions have also started to develop their own certificate programs and training courses, such as the Certified Revenue Management Executive from the Hospitality Sales and Marketing Association International (HSMAI). In addition, some business schools have recently started to incorporate pricing and RM into their generic management or marketing courses.

Many companies, however, still experience difficulty when it comes to finding qualified revenue managers. According to Kimes’s (2008) report, human resources problems were found to be the most critical issue facing RM from the hotel RM professional's perspective. In particular, career path development was found to be the area most in need of improvement. In a large number of companies, revenue managers mostly come from the reservation department, the sales department or the front desk, and their main role is to forecast demand, set room rates, control room inventory and manage distribution channels. Successful revenue managers should understand how to make the right decisions based on data analysis. It is especially critical that revenue managers know how to utilize available data, because there are more data available now than ever before. However, the role and responsibility of the revenue manager also needs to be extended. Cross et al. (2009) argued that RM can no longer stand alone as a tactical approach to room management and that the shift from a tactical emphasis to a strategic focus leads to broader responsibilities for RM. Although the major part of the revenue manager's job is analyzing numbers, an equally large part of their job is communicating with others about those numbers. Kimes (2011) conducted a survey of 487 RM professionals to understand the future of RM from the industry's perspective. The findings indicated that the competencies required for an effective revenue manager are to be a combination of analytical and communication skills. In addition, once revenue managers assess market conditions and existing demand to adjust pricing decisions using their analytical skills, they should be able to discuss this information in the context of the company's overall strategy (Farley, 2011). Revenue managers must prepare written reports and oral presentations with performance data and forecasting that can illustrate the company's 
direction in a digestible way. They must also propose recommendations for an organization's profit optimization and prepare to defend those recommendations both verbally and in writing.

Acquiring and retaining a talented revenue manager is one of the industry's biggest challenges today. It is essential not only to find the right RM professionals but also to train them to think about the big strategic picture of organization. Retaining and training the right revenue manager are issues closely related to corporate culture and organizational commitment. The success of RM should not be judged by RevPAR alone. Having a common understanding about what is important to the organization, how it is being measured and how the revenue manager's performance will be measured in accordance with the organizational goals helps them to focus on the key issues that are important to the business as a whole.

Thus far, the focus of research has largely been on operations, the technical sides of RM, and consumers' perceptions of RM pricing. There has been little academic attention on HR, RM training and educational issues. Schwartz and Cohen (2004a) found that the nature of the user interface influenced the way the revenue managers adjusted the computers' forecasts based on a study of 57 experienced revenue managers. Schwartz and Cohen (2004b) discovered that the uncertainty of estimates depends on the individual's years of industry experience, as well as on their gender. Noone and Hultberg (2011) conducted a survey of 82 sales and RM executives and suggested that hotels can foster better coordination between revenue management and sales by educating each group regarding the other group's responsibilities. Aubke et al. (2014) identified the antecedents and consequences of group cohesion by contrasting the communication networks of 38 revenue management teams by means of social network analysis. The study findings suggest that the revenue manager plays a more active role as an information broker so as to enhance group decision making. However, there is still much research that remains to be done on these topics.

\section{Conclusion and managerial implications}

Hospitality and tourism marketing has undergone remarkable changes over the past ten years. One of 
the major challenges faced by RM practitioners is how to look beyond traditional tactical RM techniques as part of operations management and incorporate RM at the strategic level in order to proactively engage with other management areas across the organization internally and with customers externally. Kimes (2010) rightly suggests that RM will become more strategic in nature and that it will encompass all revenue streams within the hotel. Although various scholars have made commendable efforts in shaping RM practice based on their research findings, our evaluation of recent emerging themes clearly shows that, as RM reaches its mature stage, more multidisciplinary studies are needed to achieve further theory development. In the previous sections, we identified nine major RM advancements since 2004, which also inform us about a range of managerial implications. We categorize them into eight areas of managerial shift where management attention is required to ensure RM success and the shaping of future RM practices. They are presented in Table 1 below.

Table 1 - Eight areas of managerial shift in revenue management

\begin{tabular}{|l|l|}
\hline From & To \\
\hline Revenue maximization & Profit optimization \\
\hline Revenue-centric approach & Customer-centric approach \\
\hline Demand-driven pricing & Reputation and value-based pricing \\
\hline Short-term tactical RM approach & Long-term strategic RM approach \\
\hline Focusing on room revenue & Total revenue from all yieldable sources \\
\hline Managing distributions & Channel management \\
\hline Relying on historical and predicted demand analysis & Capitalizing on the opportunities offered by big data \\
\hline Educating RM leaders & Fostering RM culture throughout the organization \\
\hline
\end{tabular}

To conclude, this paper has focussed on nine emerging themes of RM to expound RM progress in the past ten years. It also highlights eight areas of possible management shifts, which are likely to influence the future trends of RM practice. It may not be possible to detail all the factors that will directly or indirectly impact RM in the years ahead; technological advancement, distribution via social media, digital and mobile marketing and progressive business intelligence solutions such as big 
data are deemed to be the main exciting new opportunities or challenges for RM. Information systems may well remain as a key challenge to improve RM system performance and user satisfaction. However, it must be stressed that it also triggers ethical considerations and the need for compliance with local legal restrictions within which the organization is operating. It is also important to stress that from the HR perspective, educating future leaders in RM and a company's ability to acquire and to retain talented RM professionals are also considered to be crucial for future RM success. It is anticipated that a more holistic approach to RM is needed to identify revenue-generating opportunities and to optimize revenue and profit generation.

\section{Acknowledgement}

We would like to thank all academic colleagues who have shared their critical views on revenue management developments over the past decade. We are also grateful to our industry partners who have offered their opinions on the progress of RM based on their invaluable experience as well as their thoughts on the future of RM practice. Lastly, we are thankful for the insightful information provided by the members of two organizations in particular - Revenue Management and Pricing International (formerly Revenue Management Society) in the UK and Revenue Management Club in France.

\section{References}

Anderson, C.K. (2012). The impact of social media on lodging performance. Cornell Hospitality Report, 12(15), 4-11.

Aubki, F. Wöber, K., Scott, N., \& Baggio, R. (2014). Knowledge sharing in revenue management team: Antecedents and consequences of group cohesion. International Journal of Hospitality Management, 41, 149-157.

Aula, P. (2010). Social media, reputation risk and ambient publicity management. Strategy and Leadership, 38(6), 43-49.

Biehn, N. (2006). A cruise ship is not a floating hotel. Journal of Revenue \& Pricing Management, 5, $135-142$. 
Boyd, E.A.,\& Kallesen R. (2004). The science of revenue management when passengers purchase the lowest available fare. Journal of Revenue and Pricing Management, 3(2), 171-177.

Buckheister, B. (2013). Total revenue management in the year 2020: A futuristic view of optimal profitability. Hospitality Upgrade, Summer, 36-37.

Chan, W.W., \& Chan, L.C. (2008). Revenue management strategies under the lunar-solar calendar: Evidence of Chinese restaurant operation. International Journal of Hospitality Management, 27, 381390.

Coleman, T. (2013) Look out revenue managers, here comes big data. Hospitality Upgrade, 6/20/2013, 36-37.

Court, D., Elzinga, D., Mulder, S., \& and Vetvik, O. J. (2009). The consumer decision journey. Retrieved from http://www.mckinsey.com/insights/marketing_sales/the consumer_decision_journey on November 22nd 2014

Cross, R.G., Higbie, J.A., \& Cross, D.Q. (2009). Revenue Management’s Renaissance. A rebirth of the art and science of profitable revenue generation. Cornell Hospitality Quarterly, 50(1), 56-81.

Dana, J.D. (2008). New directions in revenue management research. Production and Operations Management, 17(4), 399-401.

Eccless, R.G., Newquist, S.C., \& Schatz, R. (2007). Reputation and its risks. Harvard Business Review, 85(2), 104-114.

Farley, T. (2011). The future of revenue management is now. Retrieved from http://www.hotelnewsnow.com/Article/7162/The-future-of-revenue-management-is-now on November 24th 2014.

Farley T. (2013). Take it further...Total hotel revenue management. Retrieved from http://www.hsmai.org/knowledge/summary.cfm?ItemNumber=10367 on November 4, 2014.

Fiig, T., Isler, K., Hopperstad ,C., \& Belobaba, P. (2010). Optimization of mixed fare structures: Theory and applications. Journal of Revenue and Pricing Management, 9(1/2), 152-170. 
Forgacs, G. (2010). Revenue Management, Maximizing Revenue in Hospitality Operations. American Hotel \& Lodging Educational Institute.

Guerriero, F., Miglionico, G., \& Olivito, F. (2014). Strategic and operational decisions in restaurant revenue management. European Journal of Operational Research, 237, 1119-1132.

Hendler, R., \& Hendler, F. (2004). Revenue management in fabulous Las Vegas: Combining customer relationship management and revenue management to maximise profitability. Journal of Revenue and Pricing Management, 3(1), 73-79.

Heo, C.Y., Lee, S., Mattila, A., \& Hu, C. (2013). Restaurant revenue management: Do perceived capacity scarcity and price differences matter? International Journal of Hospitality Management, 35, 316-326.

Holloway, S. (2008). Straight and level: Practical Airlines Economics. $3^{\text {rd }}$ Edition, Ashgate Publishing Ltd: UK.

Hudson, S., \& Thal, K. (2013). The impact of social media on the consumer decision process: implications for tourism marketing. Journal of Travel and Tourism Marketing, 30(1/2), 156-160.

IDeaS (2014). The future is here: IDeaS Launches Advanced Revenue Management System Business Wire, July $15^{\text {th }}$ 2014, New York.

IDeaS (2014). The new frontier in revenue management: Optimizing your function space for higher revenue and profits. White Paper. Retrieved from http://www.ideas.com/files/whitepapers/IDeaS\%20FSRM\%20White\%20Paper_The\%20New\%20Frontier\%20in\%20Revenue\%20Man agement_Function\%20Space.pdf on November 4, 2014.

Ji, L., \& Mazzarella, J. (2007). Application of modified nested and dynamic class allocation models for cruise line revenue management, Journal of Revenue \& Pricing Management, 6, 19-32. 
Kimes, S.E. (2008). Hotel revenue management: Today and tomorrow. Cornell Hospitality Report, 8, $4-14$.

Kimes, S.E. (2008). The role of technology in restaurant revenue management. Cornell Hospitality Report, 49(3), 297-309.

Kimes, S. (2010). The future of hotel revenue management. Cornell Hospitality Report, 10(14), 4-15. Kimes, S.E. (2011). The future of hotel revenue management. Journal of Revenue and Pricing Management, 10(1), 62-72.

Kimes, S.E., \& McGuire, K.A. (2001). Function-space revenue management: A case study from Singapore. Cornell Hotel and Restaurant Administration Quarterly, 42(6), 33-46.

Kimes S.E., \&.Singh, S. (2009). Spa revenue management. Cornell Hospitality Quarterly, 50(1), 8295.

Legohérel, P., Poutier, E., \& Fyall, A. (2013). Revenue management for hospitality and tourism, Goodfellow Publishers, Oxford, UK.

Licata, J.W., \& Tiger, A.W. (2010). Revenue management in the golf industry: Focus on throughput and consumer benefits. Journal of Hospitality Marketing \& Management, 19(5), 480-502.

Lieberman, W.H. (2003). Getting the most from Revenue Management. Journal of Revenue and Pricing Management, 2(2), 103-115.

Mainzer, B.W. (2004). Future of revenue management: Fast forward for hospitality revenue management, Journal of Revenue and Pricing Management, 3(3), 285-289.

Mathies, C., \& Gudergan, S. (2007). Revenue management and customer centric marketing - how do they influence travellers' choices? Journal of Revenue and Pricing Management, 6(4), 331-346.

Mauri, A.G. (2013). Hotel Revenue Management: Principles and Practices. Pearson: Milan, Italy. 
Milla, S., \& Shoemaker, S. (2008). Three decades of revenue management: what's next? Journal of Revenue and Pricing Management, 7(1), 110-114.

Niffoi, P. In Legohérel, P., Poutier, E. \& Fyall, A. (2013). Revenue management for hospitality and tourism, Goodfellow Publishers: Oxford, UK.

Noone, B.M., Kimes, S.E., \& Renaghan, L.M. (2003). Integrating customer relationship management and Revenue Management: a hotel perspective. Journal of Revenue and Pricing Management, 2(1), 721.

Noone, B.M., McGuire, K.A., \& Rohlfs, V. (2011). Social media meets hotel revenue management: opportunities, issues and unanswered questions. Journal of Revenue and Pricing Management, 10(4), 293-305.

Origin World Lab (2014). Tackling the tall tale of total revenue management. Retrieved from http://www.forsmarthotels.com/2014/07/16/total-revenue-management-still// on November 4, 2014.

Phillips, R.L. (2005). Pricing and Revenue Optimization. Stanford University Press, California

Queenan, C., Ferguson, M., \& Stratman, J. (2011). Revenue Management performance drivers: An exploratory analysis within the hotel industry. Journal of Revenue and Pricing Management, 10(2), 172-188.

Rannou, B., \& Melli, D. (2003). Measuring the impact of Revenue Management. Journal of revenue and Pricing Management, 2(3), 261-270.

Rasekh, L., \& Li, Y. (2011). Golf course revenue management. Journal of Revenue and Pricing Management, 10(2), 105-111.

Reinartz, W.J., \& Kumar, V. (2002). The mismanagement of customer loyalty. Harvard Business Review, 80(7), 4-12.

Rose, P. (2007). Revenue integrity: Delivering revenue and cost reduction benefits to airlines, Journal of Revenue and Pricing Management, 6, 71-76. 
Rothstein, M., \& Stone, A. (1967). Passenger booking levels. Proceedings of the second AGIFORS symposium, American Airline, NY.

Schwartz, Z., \& Cohen, E. (2004a). Hotel revenue-management forecasting evidence of expert judgment bias. Cornell Hotel and restaurant Administration Quarterly, 45(1), 85-98.

Schwartz, Z., \& Cohen, E. (2004b). Subjective estimates of occupancy forecast uncertainty by hotel revenue managers, Journal of Travel \& Tourism Marketing, 16(4), 59-66.

Schwartz, Z., Altin, M., \& Singal, M. (2014). Performance measures for strategic revenue management: RevPAR vs. GOPPAR. Working paper.

Smith, B., Leimkuhler, J., \& Darrow, R. (1992). Yield Management at American Airline. Interfaces, 22, 8-31.

Steinhardt, C., \& Gönsch, J. (2012). Integrated revenue management approaches for capacity control with planned upgrades, European Journal of Operational Research, 223, 380-391.

Sun, S., Gauri, D. K., \& Webster. S. (2010). Forecasting for cruise line revenue management, Journal of Revenue \& Pricing Management, 10, 306-324.

Sun, X., Jiao, Y., \& Tian, P. (2011). Marketing research and revenue optimization for the cruise industry: A concise review. International Journal of Hospitality Management, 30(3), 746-755.

Talluri, K.T., \& Van Rysin, G.J. (2005). The theory and practice of Revenue Management. Springer: New York.

Thompson, G.M. (2009). (Mythical) Revenue benefits of reducing dining duration in restaurants. Cornell Hospitality Quarterly, 50(1), 96-112.

Thompson, G.M. (2010). Restaurant profitability management: The evolution of restaurant revenue management, Cornell Hospitality Report, 51(3), 308-322. 
Thompson, G.M., \& Sohn, H.J. (2009). Time- and capacity-based measurement of restaurant revenue. Cornell Hospitality Quarterly, 50(4), 520-539.

Toh, R.S., Rivers, M.J., \& Ling, T.W. (2005). Room occupancies: cruise lines out-do the hotels. International Journal of Hospitality Management, 24(1), 121-135.

Toh, R. S., Raven, P., \& DeKay, F. (2011). Selling Rooms: Hotels vs Third-Parth Websites. Cornell Hospitality Quarterly, 52(2), 181-189.

Ventkat, R. (2009). The Era of Convergence in Revenue Management. In I. Yeoman \& U. McMahonBeattie (Ed) Revenue Management, a practical Pricing perspective. Palgravz Macmillan.

Vinod, B. (2004). Unlocking the value of Revenue Management in the hotel industry. Journal of Revenue and Pricing Management, 3(2), 178-190.

Vinod, B. (2008). The continuing evolution: Customer centric Revenue Management. Journal of Revenue and Pricing Management, 7, 27-39.

Vinod, B. (2009). The future of Airline Distribution and Revenue Management. In I. Yeoman, \& U. McMahon-Beattie (Ed) Revenue Management, a practical Pricing perspective. Palgravz Macmillan.

Von Martens, T., \& Hilbert, A. (2011). Customer-value-based revenue management. Journal of Revenue and Pricing Management, 10(1), 87-98.

Walczak, D., Mardan, S., \& Kallesen, R. (2010). Customer choice, fare adjustments and marginal expected revenue data transformation: a note on using old yield management techniques in the brave new world of pricing. Journal of Revenue and Pricing Management, 9(1/2), 94-109.

Wang, X.L. (2012). Relationship or revenue: Potential management conflicts between customer relationship management and hotel revenue management. International Journal of Hospitality Management, 31(3), 864-874. 
Wang, X.L., \& Bowie, D. (2009). Revenue management: The impact on business-to-business relationships. Journal of Services Marketing, 23(1), 31-41.

Wang, X.L., \& Brennan, R. (2014). A framework for key account management and revenue management integration. Industrial Marketing Management, 43(7), 1172-1181.

Wishlinski, B. (2006). Extracting the most benefit from a revenue management solution implementation, Journal of Revenue and Pricing Management, 5, 109-117. 